\title{
An Applied Research of Equipment Procurement Bidding Based on Fuzzy Syntheticism-A Case of Purchasing of a Certain Type of Command Vehicle Equipment as Example
}

\author{
WANG $\mathrm{Chao}^{1, \text { a }}$,YANG Kuo ${ }^{2, \mathrm{~b}}$ \\ ${ }^{1}$ Equipment Academy,Beijing 101416,China \\ ${ }^{2}$ School of Automobile, Chang'an University, Xi'an Shaanxi 710064, China \\ awangchao101416@163.com, byangkuochd@qq.com
}

Keywords: Military equipment procurement;Inviting bids;Command vehicle;Fuzzy syntheticism.

\begin{abstract}
According to the feasibility and necessity of our military equipment procurement bidding,and also the limitation of the traditional equipment procurement bidding method,this paper describes in detail the basic principle and the main steps in the bidding by using fuzzy comprehensive evaluation method.And validates the feasibility and veracity of it with a case of purchasing of a certain type of command vehicle equipment as example.
\end{abstract}

\section{Introduction}

Competition is one of the salient features of the market economy,and the bidding is an effective means to standardize the market competition,the military equipment also has the general attributes of goods.Giving full play to the function of the competition mechanism,Open, fair, impartial bidding,is conducive to breaking the monopoly,it can help to break the monopoly,the survival of the fittest,and also give full play to the efficiency of fund utilization[1,2].

The fact proved that,to some extent,the traditional mode of military equipment procurement has not adapted to the development of equipment under the condition of market economy requirements. On the one hand,the lack of competition,a single source,the equipment prices rose too fast by the monopoly management,The direct consequence is forces limited the number of less and less money to buy equipment,delay the process of modernization in the army;The "transparency"is not enough in procurement,supervision and evaluation mechanism is imperfect,thus resulting in unfair procurement,greatly influenced the manufacturer's enthusiasm,caused part of the product quality to drop,and even affect the industry's long-term development[3].According to the actual working experience of procurement bidding, this paper proposes a method of fuzzy syntheticism model in the equipment procurement bidding.

\section{Application of fuzzy syntheticism in the bidding of military equipment procurement}

The main steps of fuzzy syntheticism method for system evaluation is:

(1)Establishing evaluation organization, determine the evaluation objects.Evaluation of the organization is generally the bid assessment committee,Evaluation objects is to participate in bidding and qualified tenderers, With n: A1, A2, A3,...,the An, namely the theory of domain[4].

(2)Choosing evaluation index,establishing evaluation scale.Common and practical single-level model is mainly established by the quote,schedule,quality and reputation,and other indicators, Therefore,the evaluation index set $F=(\mathrm{f} 1, \mathrm{f} 2, \mathrm{f} 3, \ldots, \mathrm{fn})$,each of which can be seen as an indicator of a fuzzy set fi domain U.Scale evaluation of the model is divided into very reasonable,very reasonable,rational and irrational five general levels set $\mathrm{E}=(\mathrm{e} 1, \mathrm{e} 2, \mathrm{e}, \ldots, \mathrm{em})$.

(3)Determine the weight.The model evaluation system is relatively simple,using expert assessment to determine the weights $\mathrm{W}=(\mathrm{w} 1, \mathrm{w} 2, \mathrm{w} 3, \ldots, \mathrm{wn})$.In addition, the weight can be obtained through the analysis of historical data,choose the tender successful cases,rebuild its comprehensive assessment and evaluation matrix vector $\mathrm{R} S$,then the solution of the inverse problem of comprehensive evaluation,seeking $\mathrm{W}$ from the relationship in equation $\mathrm{WR}=\mathrm{S}[5]$. 
(4)Determine the fuzzy evaluation matrix (membership matrix).Membership is one of the key to determine the fuzzy comprehensive evaluation,In accordance with the established evaluation scale for assessment of each evaluation index. Is a kind of fuzzy mapping, On the same evaluation index,evaluation personnel can make different evaluations,so the evaluation results only for evaluation of article fi to make possible the evaluation scale ej to express the size,This may be the extent to which is the membership of rij.Because there are $\mathrm{m}$ evaluation scales,so there is a corresponding membership degree vector of $\mathrm{Ri}$ on the I index of fi ( $\mathrm{Ri}=\mathrm{ri1}$,ri2...rim), $\mathrm{i}=1,2, \ldots, \mathrm{n}$.The evaluation index of a tender units Ak set membership available membership matrix Rk said:

$$
R_{k}=\left[\begin{array}{cccccc}
r_{11}^{k} & r_{12}^{k} & \ldots & r_{1 \mathrm{j}}^{k} & \ldots & r_{1 \mathrm{~m}}^{k} \\
r_{21}^{k} & r_{22}^{k} & \ldots & r_{2 \mathrm{j}}^{k} & \ldots & r_{2 \mathrm{~m}}^{k} \\
\vdots & \vdots & \vdots & \vdots & \vdots & \ldots \\
r_{\mathrm{j} 1}^{k} & r_{\mathrm{j} 1}^{k} & \ldots & r_{\mathrm{ij}}^{k} & \ldots & r_{\mathrm{im}}^{k} \\
r_{\mathrm{n} 1}^{k} & r_{\mathrm{n} 2}^{k} & \ldots & r_{\mathrm{nj}}^{k} & \ldots & r_{\mathrm{rm}}^{k}
\end{array}\right]
$$

For quantitative indexes such as the project cost,time limit for a project,complete equipment, mainly through the investigation,collection and relevant material,every index data,carries on the analysis,comparison,which determine the membership degree of each index.For a qualitative indicators such as technical ability,reputation,mainly from the study of quantitative problem.Determine the evaluation set $\mathrm{V}$ and membership degree set $\mathrm{R}$,such as: $\mathrm{V}=$ \{very reasonable (0.9), very reasonable (0.7), reasonable (0.5), general $(0.3)$, no reasonable $(0.1)\}, R=\{0.0$ (poor), 0.2 (poor), 0.5 (in general),0.8 (better),1.0(good)\}.For each index scores were collected,and the average value was obtained as the desired degree of membership.In the matrix $\mathrm{Rk}$, the element $r_{\mathrm{ij}}^{k}=\frac{\mathrm{d}_{\mathrm{ij}}^{k}}{\mathrm{~d}}$, where $\mathrm{d}$ is the number of experts participating in the evaluation, $\mathrm{d}_{\mathrm{ij}}^{k}$ refers to the $\mathrm{I}$ evaluation index in the $A_{k}, f_{i}$ is the expert number scale of $e_{j}$ which the article $j$ evaluation, $r_{i j}$ value of the possibility of a large description of $e_{j}$.

(5)Calculation of the bidding unit comprehensive evaluation vector and priority.Fuzzy comprehensive evaluation of vector $\mathrm{Sk}=\mathrm{WRk}$,the bidder Ak's priority is Nk=SkET,Strictly speaking,a comprehensive assessment should use fuzzy synthetic vector operations,namely $\mathrm{S}=\mathrm{W} \bigcirc$ R. Orepresents a broad synthesis of computing,there are usually four kinds of synthetic arithmetic operator,namely $\mathrm{M}(\wedge, \vee), \mathrm{M}\left({ }^{\circ}, \vee\right), \mathrm{M}(\wedge, \oplus)$ and $\mathrm{M}\left({ }^{\circ}, \oplus\right), \mathrm{M}(\wedge, \vee)$,for the main factors determine matrix synthesis model,The " $\vee$ " said take small values in two or more numbers, while the $" \wedge "$ in the opposite.Using this operator for computing,considering only the minimum or maximum,minimum and maximum values that play a decisive role,while the median does not work, does not affect the results. $\mathrm{M}\left({ }^{\circ}, \oplus\right)$ is called the weighted average type,all the factors on the basis of its right to a major small balanced,more suitable for the requirements of the overall index case.For large projects bid in comprehensive evaluation,take co-ordinate the various factors to consider,so the use of $\mathrm{M}\left({ }^{\circ}, \oplus\right)$ operator,which is ordinary matrix multiplication,that, $\mathrm{S}=\mathrm{WR}$.

\section{Application of a purchasing case}

In this paper, based on the established model,verify the instance.Taking a certain type of emergency command vehicle equipment to invite public bidding, The military identified the base price for and duration, require the contractor to purchase equipment.There are A1, A2, A3 three vendors participate in the bidding,contract granted only one of them.At that time,invited 10 experts using the weighted comprehensive evaluating method for bid evaluation.Now the evaluation index,the weight of each index, the time interval,the score will be retained,and then uses the fuzzy syntheticism.That is,the evaluation index set $\mathrm{F}$ consists of five indicators,namely the project cost(f1),time(f2), ancillary equipment(f3), technical capacity(f4),credit(f5), the corresponding weight as shown in table 1.At the same time the scale of evaluation for 5 levels:the very reasonable 
(0.9),(0.7)is reasonable,rational(0.5), general (0.3),(0.1) is not reasonable

Table $1 \mathrm{~A}_{1}$ evaluation index weight and evaluation scale

\begin{tabular}{rcccccc}
\hline & $\begin{array}{l}\text { Evaluation } \\
\text { index }(\mathrm{F})\end{array}$ & $\begin{array}{c}\text { Project } \\
\text { cost }\left(\mathrm{f}_{1}\right)\end{array}$ & $\begin{array}{c}\text { Project } \\
\text { time }\left(\mathrm{f}_{2}\right)\end{array}$ & $\begin{array}{c}\text { Ancillary } \\
\text { equipment }\left(\mathrm{f}_{3}\right)\end{array}$ & $\begin{array}{c}\text { Technical } \\
\text { capacity }\left(\mathrm{f}_{4}\right)\end{array}$ & $\begin{array}{c}\text { Credit } \\
\left(\mathrm{f}_{5}\right)\end{array}$ \\
\cline { 2 - 7 } $\begin{array}{c}\text { Weights }(\mathrm{W}) \\
\text { Evaluation } \\
\text { scale }\end{array}$ & 0.3 & 0.25 & 0.2 & 0.2 & 0.2 \\
\cline { 2 - 7 } & 0.9 & 3 & 4 & 1 & 2 & 1 \\
\cline { 2 - 7 } & 0.7 & 2 & 3 & 2 & 3 & 3 \\
\hline 0.5 & 2 & 2 & 3 & 1 & 3 \\
\hline 0.1 & 2 & 1 & 1 & 1 & 1
\end{tabular}

According to the evaluation scale of bidding vendors, we can see from table 1,the project cost of A1 (f1) 3 experts think it is very reasonable,think is reasonable, rational and are generally 2,1 experts think it is not reasonable.Calculating the membership degree of each evaluation scale as follows:

$$
\begin{aligned}
r_{11}^{1} & =\frac{d_{11}^{1}}{d}=\frac{3}{10} ; r_{12}^{1}=0.2 ; r_{13}^{1}=0.3 ; r_{14}^{1}=0.2 ; r_{15}^{1}=0.1 ; \text { so, Rk1 }=(0.30 .20 .20 .20 .1) \\
R_{1} & =\left[\begin{array}{ccccc}
0.3 & 0.2 & 0.2 & 0.2 & 0.1 \\
0.4 & 0.3 & 0.2 & 0.1 & 0 \\
0.1 & 0.2 & 0.3 & 0.3 & 0.1 \\
0.2 & 0.3 & 0.3 & 0.1 & 0.1 \\
0.1 & 0.3 & 0.2 & 0.3 & 0.1
\end{array}\right] \quad N_{1}=S_{1} E^{T}=S_{1}\left[\begin{array}{l}
0.9 \\
0.7 \\
0.5 \\
0.3 \\
0.1
\end{array}\right]=0.586
\end{aligned}
$$

From table 1 to obtain the membership matrix R1 of A1,Accordingto the R1 to calculate the

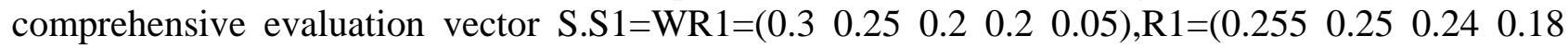
0.075).Priority of $\mathrm{A} 1$ is $\mathrm{N} 1=\mathrm{S} 1 \mathrm{ET}=0.586$.From table 2 can be drawn $\mathrm{N} 2=0.58$, according to table 3 we can see that N3=0.523.Priority 3 bidder is: N1, N2, N3,So manufacturers A1 is succeeded.This result is completely consistent by the comprehensive weighted scoring method.

Table $2 \mathrm{~A}_{2}$ evaluation index weight and evaluation scale

\begin{tabular}{ccccccc}
\hline \multirow{2}{*}{$\begin{array}{c}\text { Evaluation } \\
\text { scale }\end{array}$} & $\begin{array}{l}\text { Evaluation } \\
\text { index }(\mathrm{F})\end{array}$ & $\begin{array}{c}\text { Project } \\
\text { cost }\left(\mathrm{f}_{1}\right)\end{array}$ & $\begin{array}{c}\text { Project } \\
\text { time }\left(\mathrm{f}_{2}\right)\end{array}$ & $\begin{array}{c}\text { Ancillary } \\
\text { equipment }\left(\mathrm{f}_{3}\right)\end{array}$ & $\begin{array}{c}\text { Technical } \\
\text { capacity }\left(\mathrm{f}_{4}\right)\end{array}$ & $\begin{array}{c}\text { Credit } \\
\left(\mathrm{f}_{5}\right)\end{array}$ \\
\cline { 2 - 7 } & 0.9 & 3 & 2 & 0.2 & 0.2 & 0.05 \\
\cline { 2 - 7 } & 0.7 & 2 & 2 & 4 & 3 & 1 \\
\hline & 0.5 & 2 & 3 & 1 & 2 & 3 \\
\hline 0.3 & 1 & 2 & 1 & 1 & 4 \\
\hline & 0.1 & 2 & 1 & 1 & 1 & 0 \\
\hline
\end{tabular}


Table $3 \mathrm{~A}_{3}$ evaluation index weight and evaluation scale

\begin{tabular}{rlccccc}
\hline \multirow{2}{*}{$\begin{array}{r}\text { Evaluation } \\
\text { scale }\end{array}$} & $\begin{array}{l}\text { Evaluation } \\
\text { index }(\mathrm{F})\end{array}$ & $\begin{array}{c}\text { Project } \\
\text { cost }\left(\mathrm{f}_{1}\right)\end{array}$ & $\begin{array}{c}\text { Project } \\
\text { time }\left(\mathrm{f}_{2}\right)\end{array}$ & $\begin{array}{c}\text { Ancillary } \\
\text { equipment }\left(\mathrm{f}_{3}\right)\end{array}$ & $\begin{array}{c}\text { Technical } \\
\text { capacity }\left(\mathrm{f}_{4}\right)\end{array}$ & $\begin{array}{c}\text { Credit } \\
\left(\mathrm{f}_{5}\right)\end{array}$ \\
\cline { 2 - 7 } & 0.3 & 0.25 & 0.2 & 0.2 & 0.2 \\
\cline { 2 - 7 } & 0.7 & 2 & 3 & 1 & 2 & 3 \\
\hline & 0.5 & 2 & 2 & 3 & 3 & 3 \\
\hline 0.3 & 2 & 1 & 3 & 1 & 3 \\
\hline & 0.1 & 1 & 0 & 1 & 1 & 1 \\
\hline
\end{tabular}

\section{Conclusion}

In this paper,combined with practice of equipment procurement bidding,discusses the application of fuzzy comprehensive evaluation method in equipment procurement bidding,offers an alternative solution for equipment procurement bidding.But,we must see that for relatively simple problems,we can get a satisfactory result by fuzzy syntheticism,for the complex problem, due to consider many factors,each factor is often have different levels, should adopt the multi-level fuzzy comprehensive evaluation method or other methods of evaluation.Characteristics of different research projects bidding,selection of the appropriate decision analysis methods,improve the combination of theory and practice is the focus of research equipment procurement bidding.

\section{References}

[1] Xie X-h,Wang J-w,Yang M-j (2011) Some key issues in improvement of competitive system of Chinese military equipment procurement. J Mil Econ Acad 2011(5):155-157

[2] WeitzmanM(1980)The ratchet principle and performance incentives.BellJEcon 1980:302-308

[3] Yuan Y-q,Hu L (2008) Game analysis on military materials procurement under the lowest bid price.Logistics Technol,2008(10):259-261

[4] Jian,ZHENG (2007) Brief Introduction on Equipment Procurement.Copper E, 2007(2):9-11

[5] Wei Gang (2003) Research and analysis of equipment procurement contract theory. 2003 